\title{
CONSTRICTIVE PERICARDITIS FOLLOWING RUPTURE OF A VENTRICULAR HYDATID CYST
}

\author{
BY \\ JOHN H. HALLIDAY, ANTHONY D. JOSE, AND ROWAN NICKS \\ From The Hallstrom Institute of Cardiology, Royal Prince Alfred Hospital, Sydney, Australia
}

Infestation of man by the larval stage of Tania echinococcus is followed by growth of a primary hydatid cyst. In 1 or 2 per cent of affected patients, this cyst is located in the myocardium, and in about one-tenth of these, it ruptures at some stage into the pericardium (Dévé, 1915). Considerable experience of this complication in Uruguay was reviewed recently (Dighiero et al., 1958). Those patients who survive the acute rupture show various forms of chronic pericarditis, usually with continued growth of the primary or daughter cysts. Chronic constrictive pericarditis has been recorded, occurring in "cases of protracted evolution of an overlooked hydatido-pericardium" (Larghero, Di Bello, and Victorica, 1950). The case recorded here followed such a course, but is unusual in that spontaneous death of the parasite had apparently occurred, and effective surgical treatment was therefore possible.

\section{Case Report}

The patient, a 23-year-old girl, came from an inland area of north-eastern Australia, and was first seen by us in September 1961. In July 1958, she had gradually become ill, with fatigue, loss of weight, rapid palpitation, and recurrent left chest pain. These symptoms progressed after several months to a severe acute febrile illness with the clinical features of pericarditis. Left pleural and pericardial effusions appeared and were aspirated on several occasions, yielding a slightly turbid yellow fluid: only moderate numbers of leucocytes were seen in the centrifuged deposit, and culture was sterile.

The nature of this illness was not established. No evidence of tuberculous or malignant disease was found. Antibiotics did not seem to influence the course, and she gradually improved with conservative treatment. Three months after the onset, a raised venous pressure was first noted, but no fluid could be obtained by pericardial paracentesis at that time, despite persistent radiological enlargement of the cardiac contour. She was well enough to return to clerical work by January 1960 , but thereafter her condition remained static. She was referred to one of us (J.H.H.) in September 1961 because signs of pericardial effusion were still present. By this time, her symptoms were fatigue and palpitation on effort, but she led a relatively normal life. The physical findings were those of constrictive pericarditis, with a raised venous pressure, paradoxical pulse, and hepatomegaly without ascites or œdema. The only cardiac pulsation was felt in systole, strikingly localized to the left parasternal area in the second and third intercostal spaces. The heart sounds were quiet, without murmurs.

The chest radiograph at this time (Fig. 1, 1961) showed gross enlargement of the cardiac contour. Review of earlier films (Fig. 1) showed that in 1956 there had been an unusual contour to the left ventricle; there was a prominent swelling on its left border during the acute illness in November 1958. The electrocardiogram was similar to one taken in November 1958, showing Q waves in the antero-lateral leads, with widespread $\mathrm{T}$ wave inversion. The Casoni intradermal test was negative but the hydatid complementfixation test was strongly positive. Cardiac catheterization showed the heart chambers to be small and the pericardium grossly thickened. The hæmodynamic findings are given in the Table, and illustrated in Fig. 2. They included a paradoxical pulse, an obstructive pressure gradient in the outflow tract of the right ventricle, and features of severe constriction of both left and right sides of the heart.

At thoracotomy extensive adhesions were found in the left pleural cavity. The pericardium was distended with $700 \mathrm{ml}$. of creamy purulent fluid containing numerous collapsed daughter cysts. The heart was 


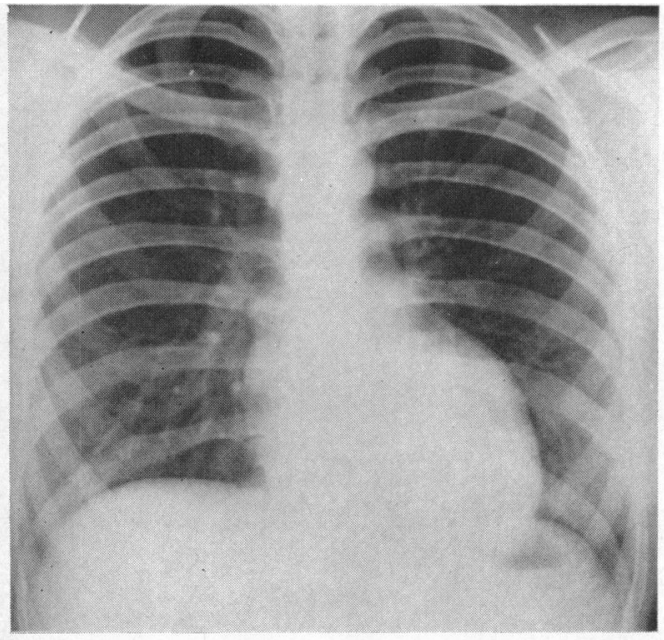

1956

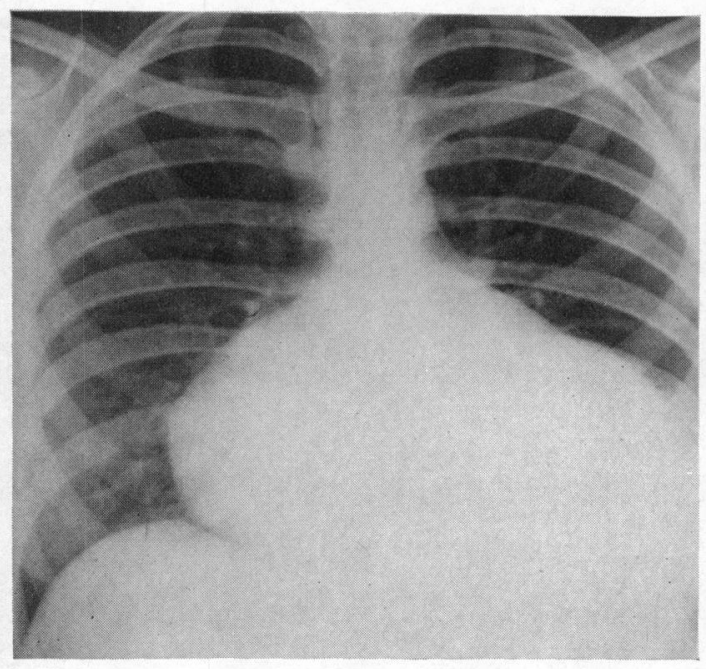

1961

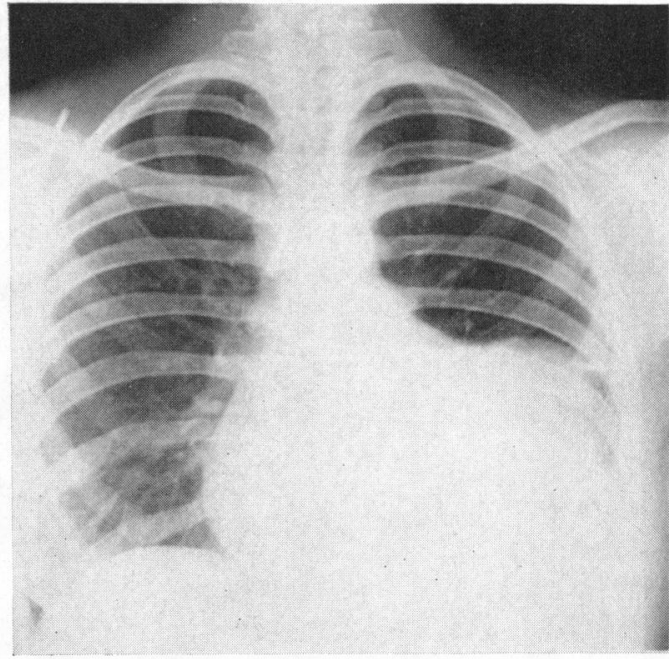

1958

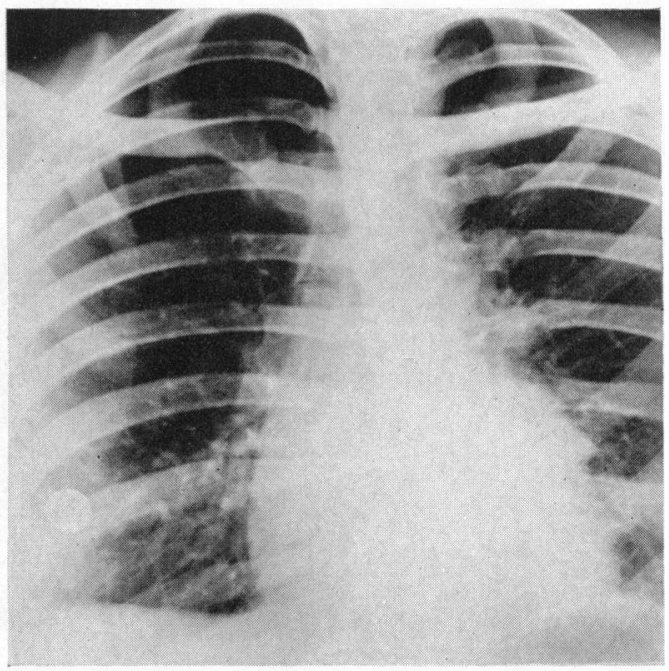

1962

FIG. 1.-Serial chest radiographs. Top left, 1956: film taken for routine reasons before any symptoms had appeared Top right, 1958: film taken during the initial acute illness, shortly after left pleural and pericardial fluid aspiration. Bottom left, 1961 : film taken at the time of hæmodynamic investigation. Bottom right, 1962: film taken in July 1962 , nine months after operation.

small and both layers of pericardium were grossly thickened and fibrotic. The thick visceral pericardial envelope was removed from the ventricles and atria, and a large swelling then became visible in the upper anterior wall of the left ventricle near its junction with the atrium. The right ventricular outflow and pulmonary artery were displaced upwards and forwards. An incision was made into the swelling, and $100 \mathrm{ml}$. of purulent fluid containing degenerate daughter cysts were removed. No germinal membrane was evident, the lining wall consisting of fibrous tissue. The cyst cavity was about $3 \mathrm{in} .(7.6 \mathrm{~cm}$.) in diameter, and with the finger inserted, the ventricular septum could be felt below and in front, and the right ventricular outflow tract and pulmonary artery above and in front. The cavity was syringed with saline and sprayed with neotracin, and the incision into the cyst left widely open. The two pleural cavities were closed with drainage. Blood 
TABLE

HÆMODYNAMIC FINDINGS

\begin{tabular}{llll|l}
\hline \multicolumn{2}{l}{ Right atrium (mean) } & $\ldots$ & $\ldots$ & $24 \mathrm{~mm} . \mathrm{Hg}$ \\
Right ventricle & $\ldots$ & $\ldots$ & $\ldots$ & $54 / 12-24 \mathrm{~mm} . \mathrm{Hg}$ \\
Pulmonary artery & $\ldots$ & $\ldots$ & $\ldots$ & $40 / 23 \mathrm{~mm} . \mathrm{Hg}$ \\
Left atrium (mean) & $\ldots$ & $\ldots$ & $25 \mathrm{~mm} . \mathrm{Hg}$ \\
Left ventricle & $\ldots$ & $\ldots$ &. & $110 / 16-26 \mathrm{~mm} . \mathrm{Hg}$ \\
Brachial artery & $\ldots$ & $\ldots$ & $\ldots$ & $127 / 80 \mathrm{~mm} . \mathrm{Hg}$ \\
Cardiac output & $\ldots$ & $\ldots$ & $\ldots$ & $4 \cdot 11 . / \mathrm{min}$. \\
Heart rate & $\ldots$ & $\ldots$ & $\ldots$ & 84 beats $/ \mathrm{min}$. \\
\hline
\end{tabular}

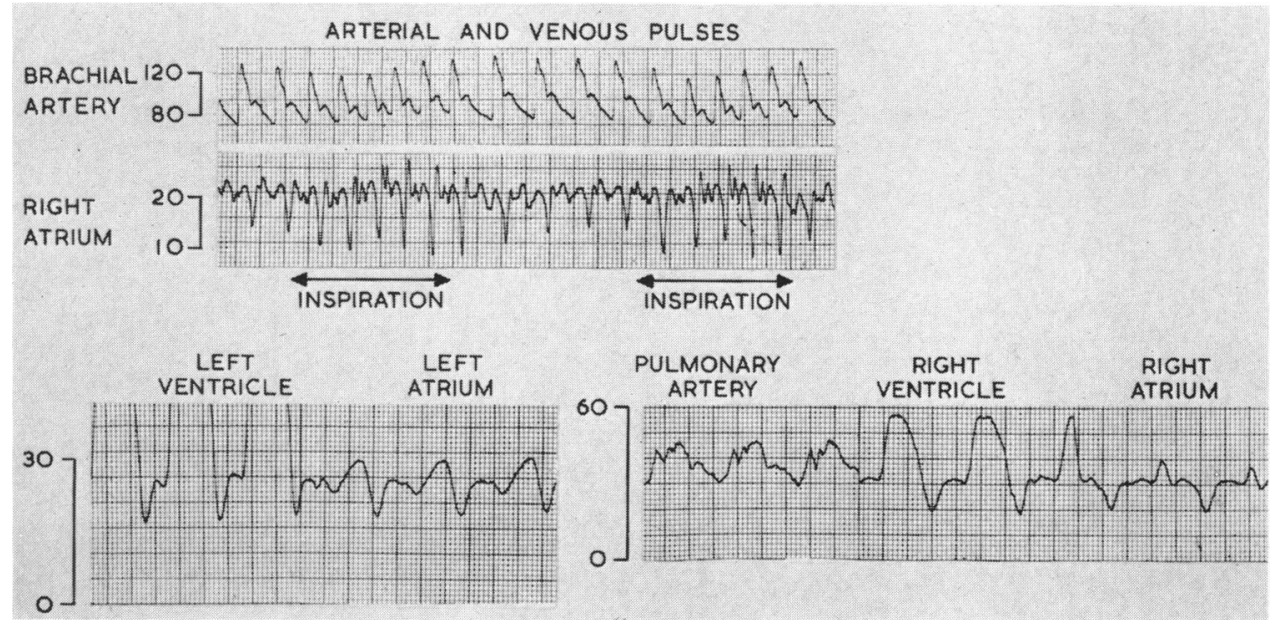

Fig. 2.-Pressure records obtained by cardiac catheterization. Above: abnormal diminution of pulse pressure in the brachial artery during inspiration, with increased pulsation in the right atrium. Below: pressure contours in the left and right heart chambers, showing impaired diastolic filling on both sides of the heart, and a systolic pressure gradient between right ventricle and pulmonary artery.

loss was considerable for 24 hours, and a clotted hæmothorax on the right side needed removal two days later. Otherwise her post-operative course was uneventful.

The fluids removed from the pericardial and cyst cavities were identical, and contained polymorph pus cells; but no hydatid elements were found. Culture was sterile.

On discharge five weeks after operation, the venous pressure was almost normal, and there was no hepatomegaly. The radiograph showed an almost normal-sized heart, with a rounded opacity projecting from the left cardiac border.

Now, one year after operation, she remains well. Radiologically, the opacity on the left cardiac border has shrunken considerably in size (Fig. 1, 1962).

\section{Discussion}

Rupture of a myocardial hydatid cyst into the pericardium is commonly followed by the evolution of daughter cysts and progress of the disease (Dighiero et al., 1958), although the latent interval between these events was five years in a case reported by Hueston (1952). The factors determining survival or death of the parasite are not known. Although secondary bacterial infection would be one obvious cause of death, involuted primary cysts are found by chance at autopsy often enough to suggest that other mechanisms can be responsible.

Death of the parasite was suggested in the present case by the failure to find active hydatid 
elements in the pericardial pus both during the initial illness and at operation, by the negative Casoni test, and by the inactive appearance of the lesion and of the daughter cysts at operation. The patient's future will clearly depend upon secure healing of the defect in the left ventricular wall, and on the absence of recurrent hydatid disease, either in the heart or elsewhere.

\section{Summary}

The clinical, hæmodynamic, and surgical features of a case of chronic constrictive pericarditis are presented. This was caused by involuted hydatid disease of the pericardium following rupture of a cyst in the left ventricular wall.

\section{References}

Dévé, F. (1915). Sur l'échinococcose secondaire du péricarde. C.R. Soc. Biol. (Paris), $78,734$.

Dighiero, J., Canabal, E. J., Aguirre, C. V., Hazan, J., and Horjales, J. O. (1958). Echinococcus disease of the heart. Circulation, 17, 127

Hueston, J. T. (1952). Hydatid disease of the pericardium. Aust. Ann. Med., 1, 186.

Larghero, P., Di Bello, R., and Victorica, A. (1950). Pericarditis constrictiva hidática. Bol. Soc. Cirug. Rosario, $21,17$. 